5-1-1975

\title{
Double Rainbow and Dark Band in Searchlight Beam
}

\author{
J. Harsch
}

Jearl D. Walker

Cleveland State University

Follow this and additional works at: https://engagedscholarship.csuohio.edu/sciphysics_facpub

Part of the Physics Commons

How does access to this work benefit you? Let us know!

\section{Publisher's Statement}

Copyright 1975 American Association of Physics Teachers. This article may be downloaded for personal use only. Any other use requires prior permission of the author and the American Association of Physics Teachers. The following article appeared in American Journal of Physics 43 (1975): 453-455 and may be found at http://ajp.aapt.org/resource/1/ajpias/v43/i5/ p453_s1?isAuthorized=no.

\section{Original Citation}

Harsch, J. and Jearl D. Walker. "Double Rainbow and Dark Band in Searchlight Beam." American Journal of Physics 43 (1975): 453-455.

\section{Repository Citation}

Harsch, J. and Walker, Jearl D., "Double Rainbow and Dark Band in Searchlight Beam" (1975). Physics Faculty Publications. 136.

https://engagedscholarship.csuohio.edu/sciphysics_facpub/136

This Article is brought to you for free and open access by the Physics Department at EngagedScholarship@CSU. It has been accepted for inclusion in Physics Faculty Publications by an authorized administrator of EngagedScholarship@CSU. For more information, please contact library.es@csuohio.edu. 


\section{Double rainbow and dark band in searchlight beam}

John Harsch*

Jearl D. Walker

Department of Physics

Cleveland State University

Cleveland, Ohio 44115

(Received 16 July 1974; revised 28 August 1974)

During a light rain at night, a double rainbow and an intervening dark band may be seen in a searchlight beam (Fig. 1). As the beam sweeps the sky while rotating about a vertical axis in the normal manner, the rainbows and dark band slide up and down the beam. Such an observation was made by one of us (J.H.) and was briefly reported by the other, ${ }^{1}$ but a general description here may be of value since the calculations involved in identifying the phenomenon can be used as a student exercise in optics. To our knowledge, the searchlight rainbows have not been analyzed elsewhere.

The primary rainbow is caused by the dispersion of light at the surface of raindrops as the light enters and leaves the surfaces. ${ }^{2-5}$ Inside the drops there is a single reflection of the light (Fig. 2). Dispersion is similar for the secondary rainbow, but there are two reflections of the light inside the drops (Fig. 2). The difference in geometry of the light paths for these two cases results in a color sequence for the secondary rainbow that is the reverse of that for the primary rainbow (Fig. 3). According

Fig. 1. Rainbows and dark band in the searchlight beam.

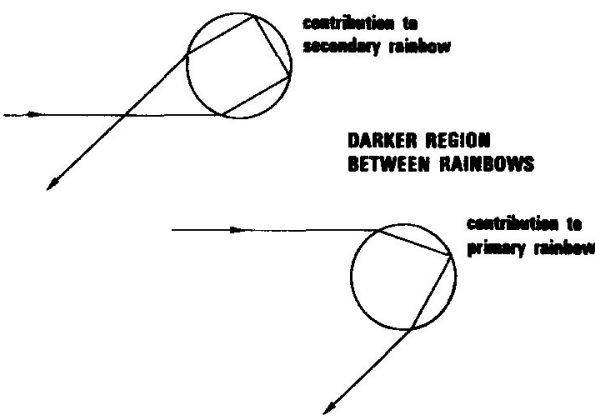

Fig. 2. Deviation of light rays to give the rainbows.

to the Cartesian theory of the rainbow, ${ }^{2-5}$ the rays that suffer the least deviation in the drops result in the greatest intensity of light scattered by the drops. The geometry of least deviation places the red arc of the primary rainbow at about $42^{\circ}$ and that of the secondary rainbow at about $51^{\circ}$ from the antisolar point (Fig. 3). There are, of course, rays leaving the drops at other angles, but they are less concentrated. However, those other rays do not leave the drops to contribute light to the observer between the two rainbows, and the observer sees that portion of the sky as darker than inside the primary and outside the secondary rainbows (Fig. 2).

In the searchlight beam both primary and secondary rainbows and the intervening dark band were seen (Fig. 1). As the beam rotated through angle $\phi$, both the rainbows and the dark band moved up and down the beam. As we shall show, for some angles $\theta$ of the beam with the vertical, the rainbows and dark band disappear on the far side of the rotation from the observer. In general, however, searchlight operators maintain $\theta$ at a small

Fig. 3. Angles between observed rainbows and a line between the sun and the antisolar point.

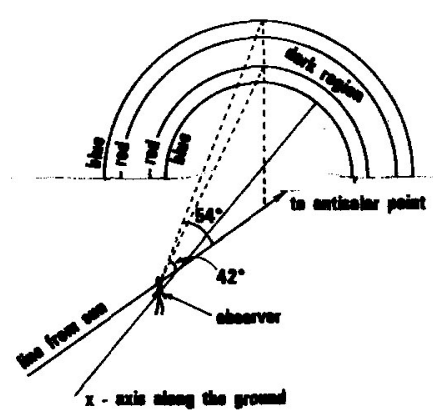


enough value (about $45^{\circ}$ ) that the disappearance does not occur.

After the searchlight rainbows had been observed, we initially guessed that the phenomenon was a rainbow effect because of the reversal of colors in the two colored bands with an intermediate dark band. A curious feature, however, was that the primary rainbow appeared higher in the sky than the secondary rainbow (Fig. 1), which is normally not the appearance with sunlight rainbows (Fig. 3 ). If the sky away from the sun is filled with drops, the rainbows should not result from drops at any particular distance from the observer. All of the drops in the direction of the rainbows and as distant as several miles should contribute to the observed colors. In a casual interpretation of the scene, however, an observer may erroneously think that the colors originate at a particular distance from him and that the secondary bow is at a greater altitude than the primary bow. The situation in the searchlight case is different in that the beam clearly limits the participating drops to those in the beam. The scattering of light is exactly the same as with sunlight, and the light rays of the secondary bow are at a greater angle from the beam $\left(51^{\circ}\right)$ than are the light rays of the primary bow $\left(42^{\circ}\right)$. To be at a greater angle from the beam means that the secondary bow will be closer to the searchlight than the primary bow. Since the beam is angled upward, being closer to the searchlight means being closer to the ground. Hence, in the searchlight rainbow case, the secondary bow will appear to be and will be correctly interpreted as being lower than the primary bow.

A second point of identification came in explaining why the rainbows slid up and down the searchlight beam as the searchlight rotated. We have chosen to follow the position of the primary bow's red arc to illustrate this movement of the rainbows. Figure 4 shows the geometry involved in calculating the position of the primary red arc. We have calculated the ratio of the red arc's distance along the beam, $r$, to the distance from the observer to the searchlight, $d$. Both observer and the searchlight are assumed to be on level ground, though modifications for other situations are easily made.

We wish to find an expression for $r / d$ as a function of $\theta$ and $\phi$ so that the position of the primary red arc can be found for any given orientation of the beam. Inspection of the triangle in Fig. 4 yields

$$
d / \sin \Omega=r / \sin (\pi-A-\Omega) .
$$

The angle between the beam and the observer's line of sight to the red arc, $\Omega$, is about $42^{\circ} \cdot{ }^{2-5}$ After expansion of the sine function, we have

$$
r / d=\sin A \cot \Omega+\cos A
$$

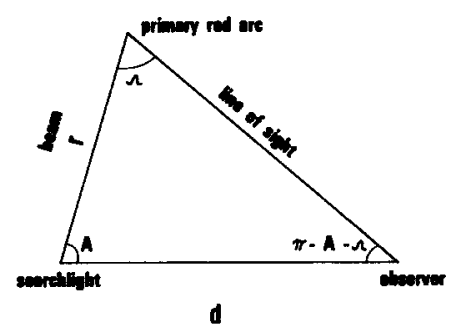

Fig. 4. Plane defined by the searchlight beam and the line of sight to the red arc of the primary rainbow.

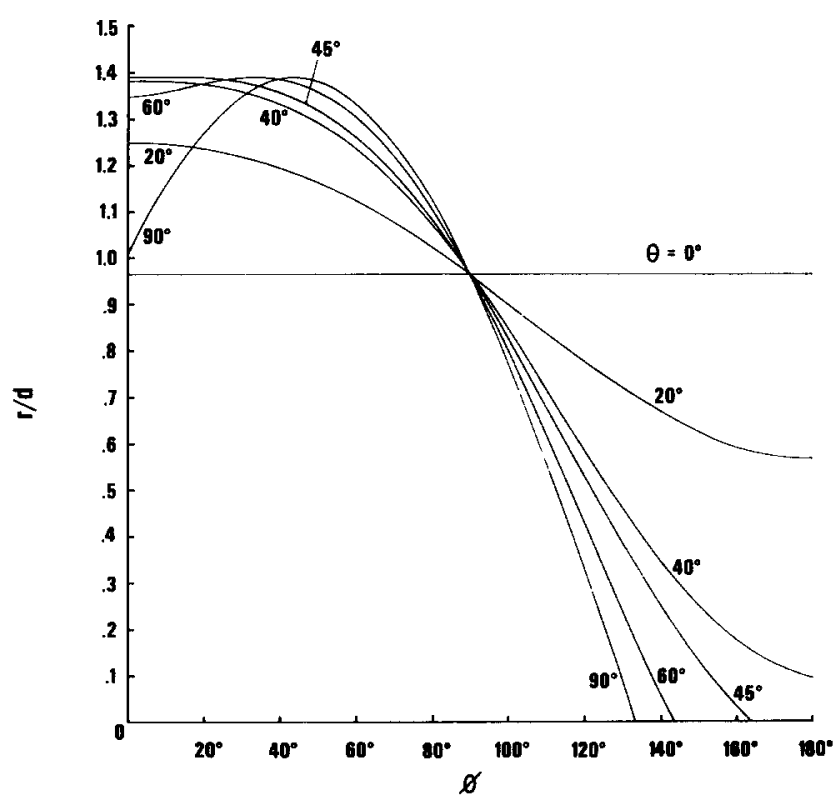

Fig. 5. Ratio $r / d$ of primary red arc.

The angle $A$ is related to $\theta$ and $\phi$ by

$$
\cos A=\sin \theta \cos \phi .
$$

Thus, for any given orientation of the beam-that is, for any given $\theta$ and $\phi$-the ratio $r / d$ can be found by (a) solving Eq. (3) for $A$ and (b) substituting $A$ into Eq. (2) for r/d.

Figure 5 gives the ratio $r / d$ for a front-to-rear halfrevolution of the beam $\left(0 \leqslant \phi \leqslant 180^{\circ}\right)$ and for several values of $\theta$, the beam's angle from the vertical. The result for $45^{\circ}$ is consistent with the observations made of a searchlight rainbow in which $\theta$ was approximately $45^{\circ}$. Note that for some values of $\theta$ the rainbows disappear on the far side of the searchlight from the observer.

We have not taken into account any minimum distance the observer should be from the raindrops before the rainbow colors can be distinguished. Minnaer $t^{6}$ reports a rainbow which was only several yards from the observer. In the observation of a searchlight rainbow made by one of us, the colors were seen when $\phi=0^{\circ}$-that is, when the beam was directed overhead. The angle to the vertical was about $45^{\circ}$, and $d \approx 100 \mathrm{ft}$. Hence, the colors were distinguishable when the distance between observer and raindrops was about $100 \mathrm{ft}$.

Additional observations and questions follow.

(1) What is the polarization of the searchlight rainbows? Using a polarizing filter, find the polarization as the searchlight swings around the vertical.

(2) Are the supernumerary bows, which are due to light interference, ${ }^{7-9}$ present? These bows are violet ones normally seen inside the primary bow and, more rarely, outside the secondary bow.

(3) The light rays from the searchlight are not perfectly parallel. How will the small divergence of the rays affect the colors to be seen in the searchlight rainbows?

(4) The sun is not an infinitely distant point source of light, and its finite size may affect the colors in the normal sunlight rainbows. ${ }^{10}$ How large would the sun have to be in our sky before our rainbows would disap- 
pear? As the sun expands in its evolution to a red giant, it will eventually reach this critical size.

Acknowledgments. We would like to thank Professor George Ficken and Professor Karl Casper for several helpful suggestions in the writing of this note. This work was supported in part by a grant from the Center for Effective Learning at Cleveland State University.

*Student, Electrical Engineering Department.

IJ. Walker, The Flying Circus of Physics (Wiley, New York, 1975).
${ }^{2}$ R. A. R. Tricker, Introduction to Meteorological Optics (American Elsevier, New York, 1970), Chaps. 3, 6.

${ }^{3}$ W. J. Humphreys, Physics of the Air (Dover, New York, 1964), pp. 466-500.

${ }^{4} \mathrm{M}$. Minnaert, The Nature of Light and Colour in the Open Air (Dover, New York, 1954), pp. 169-190.

${ }^{5}$ R. J. Whitaker, Phys. Teach. 12, 283 (1974).

${ }^{8}$ Reference 4, p. 169.

${ }^{7}$ Reference 2, pp. 169-190.

${ }^{8}$ Reference 3, p. 483.

${ }^{9}$ Reference 4, p. 172.

${ }^{10}$ Reference 4, p. 178. 